\title{
Corpo estranho na nasofaringe: a propósito de um caso
}

\section{Foreign body in nasopharynx: regarding a case}

\author{
Fernando P. G. Sobrinho', Alena M. B. Jardim², \\ Iara C. de Sant'Ana33, Hélio A. Lessa4.
}

\section{Palavras-chave: corpo estranho, nasofaringe,} laringe, radiografia do pescoço.

Key words: foreign body, nasopharynx, larynx, neck radiography.

\section{Resumo / Summary}

A

ingestão acidental de corpo estranho constitui um problema comum nas unidades de emergência e pronto atendimento, principalmente em crianças. Embora raro, um corpo estranho supostamente deglutido ou aspirado pode ser projetado e impactar-se na nasofaringe, existindo, a respeito, alguns relatos de caso na literatura. 0 exame clínico e o estudo radiológico de rotina podem não evidenciar qualquer anormalidade. Portanto, neste relato de caso, os autores recomendam a realização de radiografia do cavum e/ ou a visualização da rinofaringe, executada com cautela, utilizando-se o espeIho de García, telescópio tipo Hopkins ou naso-fibroscópio flexível nos casos em que a radiografia cervical não evidenciar adequadamente a nasofaringe, sendo a visualização instrumental particularmente importante na presença de corpo estranho radiotransparente. 0 diagnóstico precoce se impõe, haja vista a possibilidade de significativas complicações.

\begin{abstract}
comum
he accidental ingestion of foreign body establish a comum problem in the emergency room and prompt attending services, especially in childhood. Althought rare, a foreign body reputed swallowed or inhaled can be projected and lodge in nasopharynx. The physical examination and standard radiologic screening incidences may don't evidence any abnormality. Therefore, the authors of this case report recommend that a cavum roentgenogram and/or cautions rhinopharynx visualization with Garcia's mirror, Hopkins type telescopes or flexible naso-fibroscope should be performed in these cases where cervical radiographic study don't show properly the nasopharynx above all important in radiolucents foreign bodies avaliation. The early diagnostic is necessary to avoid major complications.
\end{abstract}

\footnotetext{
${ }^{1}$ Médico colaborador do Serviço de O torrinolaringologia do Hospital das Clínicas - Universidade Federal da Bahia. Médico O torrinolaringologista do Serviço de Emergência do Hospital Geral do Estado - HGE. ${ }^{2}$ Ex-médica estagiária do Serviço de Emergência Pediátrica do Hospital Geral do Estado - HGE. ${ }^{3}$ Médica do Serviço de Emergência Pediátrica do Hospital Geral do Estado.

${ }^{4}$ Professor Doutor da Disciplina de Otorrinolaringologia da Faculdade de Medicina da Universidade Federal da Bahia e Chefe do Serviço de Otorrinolaringologia do Hospital das Clínicas da Universidade Federal da Bahia.

Trabalho realizado pelo Serviço de O torrinolaringologia do Hospital das Clínicas da Universidade Federal da Bahia e Hospital Geral do Estado (Salvador - Bahia). Endereço para Correspondência: Fernando P. G. Sobrinho, CD. Rec. dos Pássaros, R3, B29A, 301, Cabula 41.150-050 - Salvador Ba. E-mail: fpgsobrinho@bol.com.br

Artigo recebido em 01 de fevereiro de 2002. Artigo aceito em 05 de julho de 2002.
} 


\section{INTRODUÇÃO}

Corpos estranhos no trato aerodigestivo constituem um problema frequente em serviços de emergência e pronto atendimento, sobretudo na faixa etária pediátrica. Por outro lado, também podem determinar complicações graves e, portanto, exigem avaliação e manejo adequados.

Comumente, um paciente com história de ingestão acidental de corpo estranho é investigado pelo exame físico e submetido à radiologia complementar, que geralmente inclui radiografia do pescoço, tórax e abdômen.

Embora raro, um corpo estranho supostamente deglutido ou aspirado, pode ser projetado, impactar e fixarse na nasofaringe, mantendo-se clinicamente silencioso e não ser claramente evidenciado por incidências radiológicas de rotina, dificultando o pronto diagnóstico e aumentando 0 risco de morbidade.

Relatamos um caso em que uma criança com história de ingestão acidental de corpo estranho foi avaliada por uma radiografia do cavum que evidenciou a presença do corpo estranho na nasofaringe.

\section{REVSÃO DA LITERATURA}

Há, na literatura consultada, poucos relatos sobre corpos estranhos na nasofaringe, sendo a maioria em idioma russo e sem resumo disponível em língua inglesa. Porém, sabe-se que é rara sua ocorrência.

Gómez ${ }^{1}$ relata um caso de ingestão de objeto plástico com esofagoscopia exploradora normal, a partir da qual seguiram-se cinco meses de rinorréia purulenta unilateral e halitose tratada como sinusite maxilar crônica, confirmada radiologicamente. Ao final deste período, um corpo estranho foi observado no cavum da criança à rinoscopia posterior.

Em 1988, Parker et al. 2, em Bristol, Reino Unido, relataram dois casos com história de ingestão de moedas de cinco centavos de libra esterlina, em pacientes com 2 e 6 anos de idade, respectivamente, tendo o primeiro um intervalo de 7 semanas entre a primeira avaliação médica e o diagnóstico definitivo de anormalidade na nasofaringe, mesmo tratando-se de um objeto radiopaco. Nenhum destes dois pacientes apresentava sinais ou sintomas e o exame físico e radiológico iniciais não revelaram anormalidades. 0 diagnóstico definitivo foi obtido com estudo radiológico do cavum.

Anteriormente, Dayal e Singh ${ }^{3}$ haviam relatado, em 1970, uma série de três casos, dos quais dois pacientes, com idades de 3 e 18 anos, se apresentavam clinicamente com epistaxis, sendo os corpos estranhos um brinquedo e um sanguessuga de água doce, respectivamente. Num terceiro paciente, vítima de acidente com arma de fogo e com significativas lesões na face, foi constatada radiologicamente a existência de objeto metálico no rinofaringe.

Gendeh e Gibb ${ }^{4}$ descrevem um paciente malaio do sexo masculino, com 24 anos de idade, com rinorréia purulenta unilateral que começou seis meses após um grave acidente automobilístico. Com o diagnóstico de sinusite maxilar refratária, ratificada radiologicamente, e seqüelas traumáticas, foi submetido a procedimento cirúrgico, durante o qual uma rinoscopia posterior revelou a presença de fragmentos de madeira impactados na rinofaringe com até $6,7 \mathrm{~cm}$ de comprimento e 1,5 da largura, circundado por abundante flogose e secreção purulenta. As evidentes lacerações na pirâmide nasal, então cicatrizadas, foram consideradas pelos autores como a provável via de entrada daqueles objetos.

Corpos estranhos nesta localização também podem ter origem iatrogênica ${ }^{4}$, como conseqüência de procedimentos otorrinolaringológicos envolvendo fragmentos de algodão, gaze ou tampões que podem atuar como corpos estranhos. Porém, é possível que estas últimas ocorrências sejam mais provavelmente relatadas de forma injuriosa na literatura leiga e sensacionalista.

\section{RELATO DE CASO}

Paciente do sexo feminino, 2 anos de idade, foi encaminhada ao serviço de emergência com suspeita de ingestão de um brinquedo, uma esfera de vidro opaco (regionalmente conhecida como "bola de gude" - um entretenimento freqüente entre crianças maiores e adolescentes) há aproximadamente duas horas. Genitora nega dispnéia ou sialorréia na criança. Ao exame físico, mostrava-se calma e brincando, em contraste com a aflição materna. Apresentava uma respiração ruidosa, semelhante à observada em al guns respiradores bucais, mas mostrava-se eupnéica. Extremidades acianóticas. A rinoscopia anterior e a mobilidade cervical não mostraram qualquer anormalidade. Havia um leve abaulamento na zona de transição entre 0 palato mole e o palato duro em direção à cavidade oral, evidenciado à orofaringoscopia. 0 exame físico segmentar restante não evidenciou alterações.

A paciente já havia sido submetida a radiografia de abdômen, tórax e do pescoço, sendo esta em incidência póstero-anterior (PA) e perfil, e à endoscopia digestiva alta, que foi normal. Apenas a radiografia cervical, em perfil, revelava uma estranha imagem no limite posterior do cavum: uma silhueta, com dimensões discretas, que chamava atenção pela excessiva radiopacidade.

A partir do exame clínico inicial e radiológico prévio, foi requisitado uma radiografia da nasofaringe, rapidamente obtida, que evidenciou a presença de imagem radiopaca, arredondada, ocupando a luz do rinofaringe (figura 1), documentando a existência de corpo estranho.

O corpo estranho foi removido por via oral com paciente sob anestesia geral e intubação orotraqueal, após prévio tamponamento da hipofaringe(figura 2). Foi de grande auxílio o uso de uma sonda de intubação delicada 


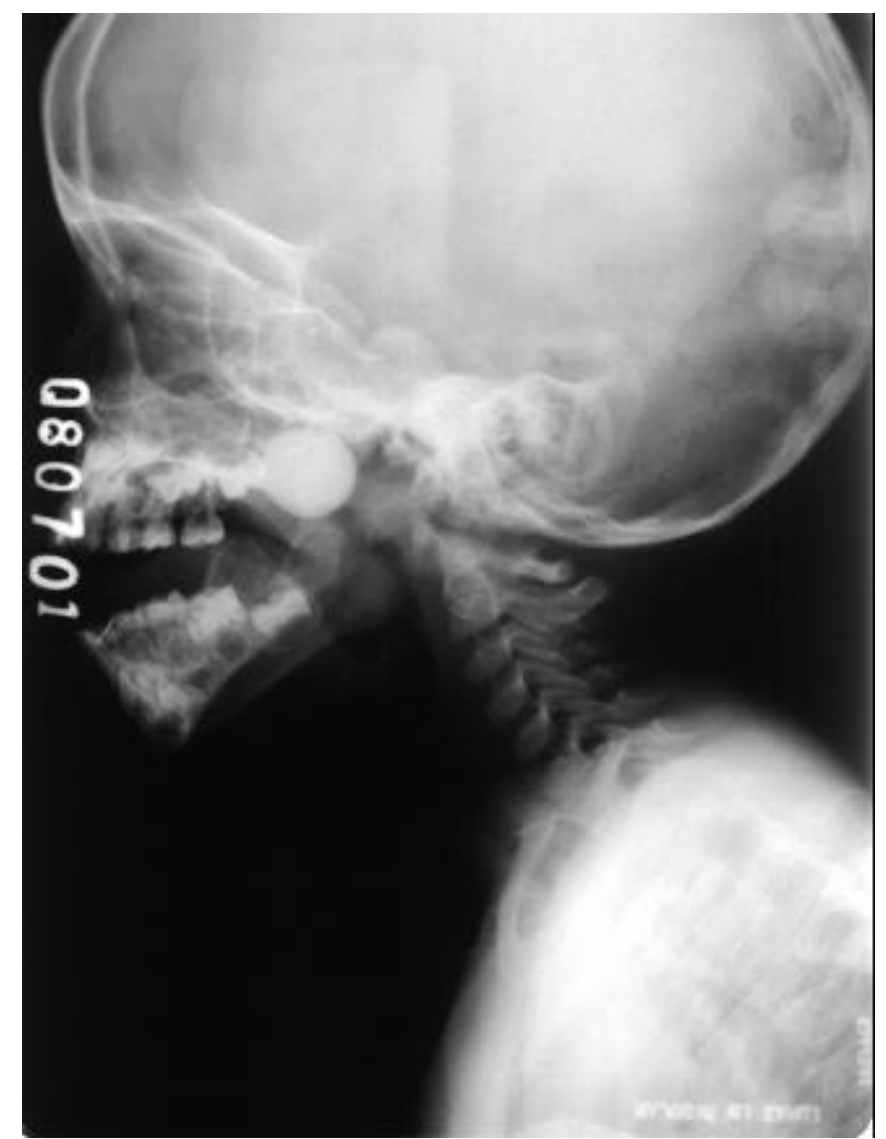

Figura 1. Estudo radiológico evidencia imagem radiopaca, arredondada, situada na nasofaringe.

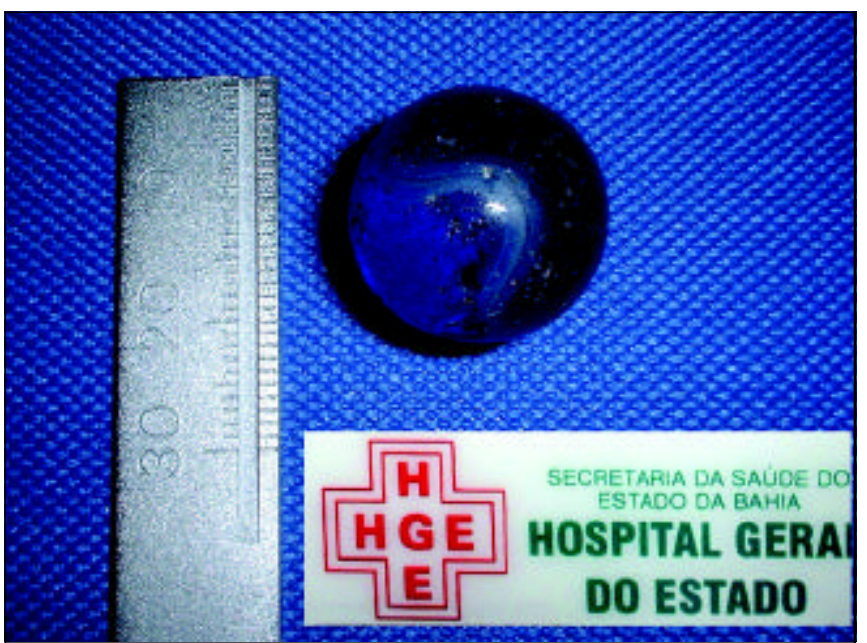

Figura 2. corpo estranho removido, esférico, vítreo e com aproximadamente $18 \mathrm{~mm}$ de diâmetro. introduzida por via endonasal, projetando o corpo estranho em direção à orofaringe associado a manobra digital via oral. 0 seguimento ambulatorial não mostrou qualquer seqüela.

\section{DISCUSSÃO}

O diagnóstico de corpo estranho acidental na nasofaringe é incomum. Por outro lado, é mais freqüente em outros sítios da via aerodigestiva como fossas nasais, amígdalas, esfíncter esofágico superior, árvore traqueobrônquica, etc.

Em geral, os corpos estranhos constituem um problema frequente na infância ${ }^{5}$. A gravidade do quadro clínico, por sua vez, habitualmente está relacionada à localização, natureza e dimensões do corpo estranho, bem como a presença ou não de complicações infecciosas, obstrutivas e inflamatórias, como a necrose adjacente por pressão, que podem estar associadas a um diagnóstico tardio. A ausência de tratamento precoce, por sua vez, pode ser fatal em alguns casos, sobretudo quando envolve órgãos como a laringe.

H arris et al. ${ }^{6}$ relatam que 66 a 77 crianças com idade inferior a 10 anos morrem anualmente nos Estados Unidos por asfixia asso ciada a alimentos impactados na laringe. Em 1989, Lima ${ }^{7}$ publicou uma série de 91 casos de aspiração de corpo estranho diagnsticados em período de 07 anos, dos quais $11(12,1 \%)$ impactavam-se na laringe, comprometendo em algum grau o espaço glótico. Destes, cinco (45\%) pacientes foram a óbito e três (27\%) evoluíram com encefalopatia hipóxica transitória, demonstrando, portanto, elevada taxa de morbi-mortalidade. 0 autor classifica genericamente a natureza dos corpos estranhos encontrados como fino e laminar ou globoso e arredondado. Refere que estes últimos estiveram relacionados à maioria dos casos fatais $e$ complicados.

Por outro lado, alguns corpos estranhos ingeridos podem impactar no trato gastro-intestinal, sobretudo em estreitamentos naturais como o esfíncter esofágico superior ou válvula íleo-cecal.

Conforme descrito previamente, embora existam relatos de longa permanência de objetos na nasofaringe, levando a complicações infecciosas menores como nasofaringites e rinossinusites, a aspiração de corpos estranhos, inclusive possível durante o sono, a partir desta localização, constitui um risco iminente e potencialmente fatal. No caso em estudo, o deslocamento do objeto esférico e sólido para o segmento mais inferior do trato respiratório e digestivo poderia ter consequências desastrosas. A respeito, Parker et al. referem que uma certa hipertonia muscular faríngea transitória pode sustentar temporariamente alguns corpos estranhos na nasofaringe, mas um posterior relaxamento muscular do palato segue-se a este estado.

Em relação ao diagnóstico, observa-se que a história clínica dos corpos estranhos situados na rinofaringe pode 
variar desde a ausência de sinais e sintomas até epistaxis e franca rinorréia purulenta, uni ou bilateral. Naqueles pacientes, ao exame físico, um objeto com dimensões suficientes pode abaular o palato mole e ter sua presença sugerida à orofaringoscopia, como observado no caso em estudo. Por sua vez, a impactação de corpos estranhos no esôfago pode levar a sialorréia, alterações da lordose cervical, disfonia, disfagia e dor local que pode limitar a mobilização cervical passiva ou ativa. Finalmente, uma rinorréia purulenta e fétida unilateral ou epistaxis pode ser o único achado na presença de um corpo estranho na fossanasal 8 .

No pronto atendimento, usualmente a radiografia de pescoço, em PA e perfil, tórax e abdômen são solicitados pelo médico pediatra ou clínico para investigar as suspeitas de ingestão de um corpo estranho, após adequado exame clínico ${ }^{2}$. Deste modo, os corpos estranhos, principalmente os radiopacos, podem ser facilmente evidenciados no esôfago. Entretanto, como a radiografia cervical pode não delimitar de forma satisfatória boa parte da nasofaringe, a constatação de anormalidade nasofaríngea pode ser perdida e o diagnóstico de corpo estranho nesta localização comprometido, como observado em alguns relatos na literatura revisada. A raridade de corpos estranhos nesta topografia também favorece o baixo grau de suspeição nestes casos.

A rinoscopia posterior transoral com espelho de García ou telescópio tipo Hopkins angulado 30 ou 70 graus, a endoscopia nasal rígida com telescópio tipo Hopkins com angulação de 0 ou 30 graus ou mesmo a naso-fibroscopia flexível seriam de inestimável valor no diagnóstico de alguns corpos estranhos na rinofaringe, mas não se encontram disponíveis em muitos serviços de atenção primária à saúde e mesmo em unidades de emergência, sobretudo naquelas onde inexiste a presença do otorrinolaringologista. So mamse a estes fatos as naturais dificuldades que habitualmente impossibilitam a realização de uma rinoscopia posterior clássica com espelho em crianças menores.

Entretanto, estes procedimentos endoscópicos devem ser realizados com extremo cuidado e sob condições adequadas a fim de não precipitar o deslocamento de um corpo estranho impactado na rinofaringe para a via aerodigestiva inferior. Nos relatos revisados não encontramos referências quanto ao uso da endoscopia no diagnóstico de corpo estranho na nasofaringe, talvez por serem, em sua maioria, publicações anteriores à ampla popularização daqueles instrumentos endoscópios e pelo satisfatório resultado obtido com a avaliação radiológica da rinofaringe na maioria dos casos.

\section{CONCLUSÕES}

Os pacientes com antecedentes de ingestão de corpos estranhos e avaliação radiológica inicial irrelevante, onde a radiografia cervical delimite inadequadamente a nasofaringe, deveriam ser submetidos a um estudo radiológico do cavum e/ ou a cautelosa rinoscopia posterior convencional ou endoscópica endonasal/transoral, principalmente na suspeita de objetos radiotransparentes. A ausência de diagnóstico correto nestes casos pode levar a significativas complicações.

\section{REFERÊNCIASBIBUOGRÁFICAS}

1. Gómez DM. Cuerpo extraño en cavum. Anales ORL Iber - Amer, XIV, 1: 105-107, 1987

2. Parker AJ, Bingham BJ, Osborne JE. The swallowed foreign body: is it in the nasopharynx? Postgrad Med J 64: 201-203, 1988.

3. Dayal D, Singh AP. Foreign body nasopharynx. J Laryngol Otol 84: 1157-1160, 1970.

4. Gendeh BS, Gibb AG. An unusual foreign body presenting in the nasopharynx. J Laryngol Otol 102: 641-642, 1988.

5. François M, Hamrioui R, Narcy P. Nasal foreign bodies in children. Eur Arch Otorhinolaryngol 255: 132-134, 1998.

6. Harris CS, Baker SP, Smith GA, et al. Childhood asphyxiation by food. JAMA, 255: 2231-2235, 1984.

7. Lima JA. Laryngeal foreign bodies in children: a persistent, lifetreatening problem. Laryngoscope 99: 415-420, 1989.

8. Tong MCF, Ying SY, Hasselt CA. Nasal foreign bodies in children. Int J Pediatr Otorhinolaryngol 35: 207-211, 1996. 